\title{
Shallow Seismicity Patterns in the Northwestern Section of the Mexico Subduction Zone
}

\author{
Elizabeth R. Abbott (1)*, Michael R. Brudzinski (2)
}

(1) Department of Earth and Planetary Sciences, Harvard University

(2) Department of Geology and Environmental Earth Science, Miami University

* Now at Department of Geology and Environmental Earth Science, Miami University

Corresponding Author: Michael R. Brudzinski

Email: brudzimr@miamioh.edu

Phone: +1 513-529-9758

Address:

Department of Geology \& Environmental Earth Science

Miami University

501 East High St.

Oxford, OH 45056 


\begin{abstract}
This study characterizes subduction related seismicity with local deployments along the northwestern section of the Mexico Subduction Zone where 4 portions of the plate interface have ruptured in 1973, 1985, 1995, and 2003. It has been proposed that the subducted boundary between the Cocos and Rivera plates occurs beneath this region, as indicated by inland volcanic activity, a gap in tectonic tremor, and the Manzanillo Trough and Colima Graben, which are depressions thought to be associated with the splitting of the two plates after subduction. Data from 50 broadband stations that comprised the MARS seismic array, deployed from January 2006 to June 2007, were processed with the software program Antelope and its generalized source location algorithm, genloc, to detect and locate earthquakes within the network. Slab surface depth contours from the resulting catalog indicate a change in subduction trajectory between the Rivera and Cocos plates. The earthquake locations are spatially anti-correlated with tectonic tremor, supporting the idea that they represent different types of fault slip. Hypocentral patterns also reveal areas of more intense seismic activity (clusters) that appear to be associated with the 2003 and 1973 megathrust rupture regions. Seismicity concentrated inland of the 2003 rupture is consistent with slip on a shallowly dipping trajectory for the Rivera plate interface as opposed to crustal faulting in the overriding North American plate. A prominent cluster of seismicity within the suspected 1973 rupture zone appears to be a commonly active portion of the megathrust as it has been active during three previous deployments. We support these interpretations by determining focal mechanisms and detailed relocations of the largest events within the 1973 and inland 2003 clusters, which indicate primarily thrust mechanisms near the plate interface.
\end{abstract}

Keywords: seismology, Mexico, subduction, Rivera, Cocos, Middle America Trench, Jalisco Block

\title{
1. Introduction
}

The theoretical downdip limit of a plate interface seismogenic zone is marked by a transition from stick-slip to stable sliding behavior (Scholz, 2002). While there are some indications this transition in behavior can be influenced by the rheological brittleductile transition of crust or mantle rocks, ultimately the change in behavior is due to a change in frictional stability. This characterization of the seismogenic zone is particularly important in subduction zones where sudden slip in the locked zone produces the largest and most devastating earthquakes. While seismic behavior of subduction zones is variable, it is thought that the age and mechanics of the subducting plate has a large influence on the behavior of the seismogenic zone. The Mexico Subduction Zone (MSZ) can be strongly characterized by the along-strike variation in subduction geometry, ranging from more steeply dipping segments near the Rivera-Cocos plate boundary to subhorizontal segments. Though they are not well understood, flat slab regions are not uncommon globally, occurring in $10 \%$ of modern convergent margins including Guerrero and Oaxaca to the southeast of our study region (Gutscher et al., 2000; Husker and Davis, 2009; Kim et al., 2010; Pérez-Campos et al., 2008). This portion of the MSZ at the Rivera-Cocos plate boundary provides a unique opportunity to examine the seismic behavior during subduction of young lithosphere under active microplate fragmentation 
and with variable geometry that has occurred repeatedly through time along this subduction zone (Dougherty et al., 2012). Here, the young Rivera and Cocos plates are subducting beneath North America, contributing to an environment with a wide range of seismic activity including frequent large to great earthquakes, abundant microseismicity, prominent earthquake afterslip, and tectonic tremor (e.g., Schmitt et al., 2007; Schlanser et al., 2010). Despite the fact that each of these different fault behaviors could largely be influenced by slab geometry and/or controlled by stress on the plate interface, no reliable relationship has been found between these phenomena as of yet. This uncertainty fuels significant discussion around the characterization of and tectonic interactions between the subducting Rivera and Cocos plates, warranting further investigation.

In this region, the Manzanillo Trough and Colima Graben appear to occur above the boundary between the subducting Rivera and Cocos plates, adding to the intrigue of this tectonic region. Both plates consist of young ( $<11$ Myr) oceanic lithosphere, though the Rivera microplate separated from the Cocos plate 5-10 Ma (Demets and Traylen, 2000; Dougherty et al., 2012). The boundary between the two plates is still difficult to discern or interpret (DeMets and Wilson, 1997; Bandy et al., 1999; Suarez et al., 1999; Peláez Gaviria et al., 2013). The Rivera plate is subducting at $30-50 \mathrm{~mm} / \mathrm{yr}$ nearly perpendicular to the trench beneath Colima though the rate slows to $\sim 15 \mathrm{~mm} / \mathrm{yr}$ as the trajectory becomes increasingly oblique to the northwest (Kostoglodov and Bandy, 1995; DeMets and Wilson, 1997). The Cocos plate subducts at $\sim 50 \mathrm{~mm} / \mathrm{yr}$ suggesting that motion occurs between the Cocos and Rivera plates beneath the continental margin as well. The Colima Graben (5 Ma) is a generally north-south linear depression characterized by active faulting and abundant volcanism, and has been proposed to be the surface manifestation of the boundary between the Rivera and Cocos plates, marking the eastern extent of the high elevation associated with the Jalisco crustal Block (Singh et al., 1985; Bandy et al., 1995; Rosas-Elguera et al., 1996, Peláez Gaviria et al., 2013). Although much geodetic, petrologic, structural, and paleomagnetic work as been done there has been no detailed study of the subduction interface so not much is known about how subduction of young lithosphere under active microplate fragmentation influences the interaction between the subducting and overriding plates.

There have been several megathrust earthquakes in this region during modern instrumental recording. The first was the 1973 January 30 (Mw 7.6) Colima earthquake that occurred just southeast of the Manzanillo Trough and Colima Graben. It is considered a megathrust event based on a shallow thrust focal mechanism and the rupture extent has been estimated from the distribution of aftershocks (Reyes et al., 1979). The 1995 October 9 (Mw 8.0) Colima-Jalisco earthquake occurred northwest of the Manzanillo Trough, the first event to occur in this region since the 1932 June 3 (Mw 8.2) and 1932 June 18 (Mw 7.8) earthquakes (Singh et al., 1985; Pacheco et al., 1997) which are thought to have ruptured this area as well. Focal mechanisms for this event are consistent with shallow thrusting (Dziewonski et al., 1997; Escobedo et al., 1998) as well. The 1995 earthquake was also one of the first earthquakes to occur close enough to a GPS geodetic network to be able to study the coseismic and near-term post-seismic behavior of the subduction interface. Geodetic and seismologic results concur that slip was primarily above $20 \mathrm{~km}$ depth along a $150 \mathrm{~km}$ segment extending northwest from the Manzanillo Trough (Courboulex et al., 1997; Melbourne et al., 1997; Mendoza and Hartzell, 1999; Hutton et al., 2001). The most recent megathrust event to occur in this 
region was the 2003 January 22 (Mw 7.2) Tecomán earthquake off shore from Colima. Focal mechanisms indicate shallow interplate thrusting (Yagi et al., 2004; Ekström et al., 2005) while seismic and geodetic inversions signify that the large majority of the coseismic slip was limited to an $80 \mathrm{~km}$ along-strike region bounded by the Manzanillo Trough and southernmost Colima Graben (Yagi et al., 2004; Schmitt et al., 2007). The coincidence of the 1932, 1973, 1995, and 2003 rupture edges with the Manzanillo Trough and Colima Graben may indicate that these features represent a mechanical barrier to along-strike rupture propagation.

In addition to earthquakes, episodic slow slip and tectonic tremor have been observed along the southern coast of Mexico, including some of the largest (Mw 7.5) episodic transient slip events which have been produced in the Guerrero and Oaxaca regions to the southeast of the study region (Larson et al., 2007; Brudzinski et al., 2007, 2010; Payero et al., 2008). Large slow slip recurs 1-4 years on average in Guerrero and Oaxaca, but no evidence for slow slip has been reported yet in our study region. Patches of tremor in Oaxaca and Guerrero occur more frequently, with epicenters shifted inland from slow slip between the 30-50 km plate interface contours. Tremor has been found in our study region (Schlanser et al., 2010), using the same seismic network as this study and with an approach similar to that utilized in the Oaxaca region (Brudzinski et al., 2010). The results of that study are similar to that of Ide (2012), with tremor located in a trench-parallel band with a distinct gap at the western edge of the Colima Graben.

The Mapping the Rivera Subduction Zone (MARS) deployment has provided a new opportunity to reevaluate ideas regarding this region specifically. This study seeks to further analyze the shallow $(0-80 \mathrm{~km})$ earthquakes captured by the recent seismic recording in this region in the context of results from previous seismic deployments to improve our understanding of the configuration and complicated tectonic interactions between two subducting plates in the westernmost section of the MSZ.

\section{Data and Methods}

The MARS (Mapping the Rivera Subduction Zone) experiment, composed of 50 temporary broadband seismic stations in a two dimensional grid, was an IRIS-PASSCAL deployment in southwestern Mexico from January 2006 to June 2007 (Figure 1). This 18month experiment involved the University of Texas at Austin and New Mexico State University in collaboration with colleagues at Centro De Geociencias, UNAM, and the Volcanic Observatory at the Universidad de Colima in Mexico. The overall goals of the MARS experiment were to gain a better understanding of the forces controlling the unusual tectonics of the Jalisco block and the behavior of the Rivera and Cocos plates (Soto et al., 2009; Yang et al., 2009). The deployment configuration is ideally situated to examine a $\sim 400-\mathrm{km}$ along-strike section of the seismogenic and transition zone of the plate interface. We use this dataset to establish the shallow microseismicity patterns across this unique subduction boundary, comparing to patterns observed during previous temporary deployments, as well as patterns in megathrust earthquakes, afterslip, and tectonic tremor. 


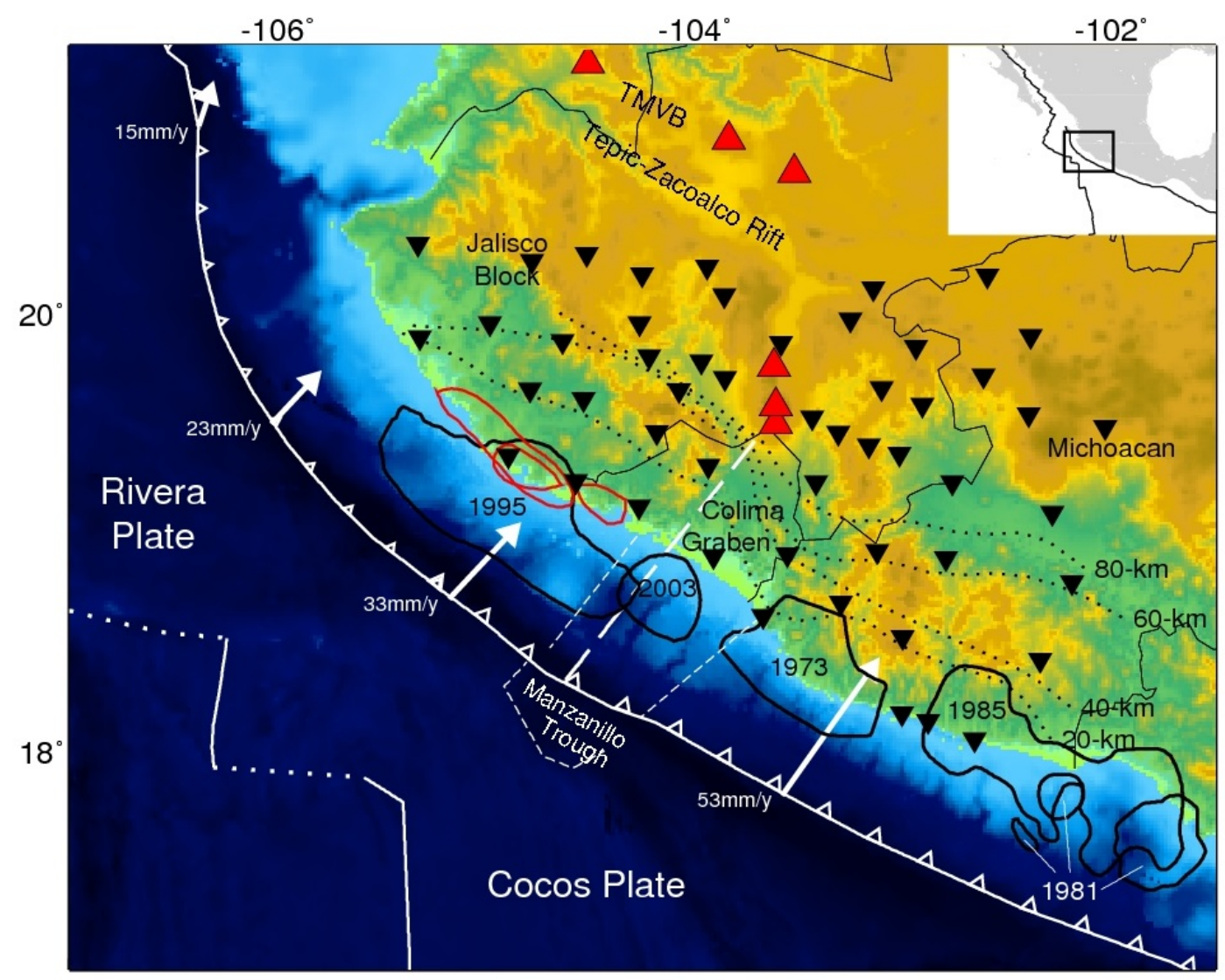

Figure 1. Map of the broadband seismic station distribution, indicated by black triangles, across the states of Jalisco, Colima, and Michoacán along the Middle America Subduction Zone. Major earthquake rupture zones as defined by previous studies (Pacheco et al., 1997; Reyes et al., 1979; Schmitt et al., 2007; Mendoza, 1993) are outlined in black. Red circles indicate an area of afterslip following the $1995 \mathrm{Mw} 8.0$ earthquake. Red triangles are volcanoes including Trans-Mexican Volcanic Belt (TMVB). Slab contours determined in this study are indicated by black dotted lines. Long dashed line near the edges of the 1995 and 2003 rupture zone indicates apparent subducted boundary between Rivera and Cocos plates (Andrews et al., 2011). Other relevant tectonic and topographical features are labeled.

In order to locate shallow seismicity, the data used in this study have been organized and analyzed using the Antelope software package (version 4.11). Processing begins by applying a multi-frequency STA/LTA detector (dbdetect) on all vertical component waveforms. We use the default Antelope parameters, including an overall SNR detection threshold of 5 and short / long window lengths of 5 s / 50 s, 2 s / 20 s, and $1 \mathrm{~s} / 10 \mathrm{~s}$ for filters of $0.5-1.2 \mathrm{~Hz}, 0.8-3.0 \mathrm{~Hz}$, and 3.0-3.0+ Hz, respectively. Detections are then investigated using the spatial grid search based associator and event locator (dbgrassoc). Nearly all default parameters are employed, including the use of the iasp91 velocity model, a $500 \mathrm{~s}$ time window, the taup phase predictor, and residual thresholds for association of $\mathrm{P}$ and $\mathrm{S}$ waves at 10 and $20 \mathrm{~s}$, respectively. The lone exception to our use of default parameters is that the minimum allowable number of stations is lowered to 4 at this stage in processing, so in effect, our minimum number of stations to associate 
and later locate an event is also decreased to 4. We found these detection and association parameters provided an appropriate balance between minimizing missed events and multiple detections of a single event.

Source locations of the associated events are then relocated with the generalized source location algorithm (genloc) using the weighted RMS methodology (Pavlis et al., 2004). This routine also provides an estimate of uncertainties in the location, depth and origin time from the covariance matrix assuming Gaussian errors. In order to obtain the best representation of seismicity in the region, we employed genloc with a 1D velocity model appropriate for this area of southwestern Mexico (Pacheco et al., 1997). We used the default parameters except that we allowed for a larger maximum distance $(5 \mathrm{~km})$ and number of hypocentral adjustments (100). To confirm the reliability, estimate the accuracy of the automated event location procedure, and determine a satisfactory uncertainty threshold, we manually reanalyzed the first $\sim 700$ events spanning two months of data. For this test, the analyst individually confirms or adjusts associations and arrival times on waveforms filtered above $5 \mathrm{~Hz}$ until a stable source location is obtained. Overall results of the manual location process have median uncertainties an order of magnitude lower than that of the automated location process $(0.1 \mathrm{~km}$ for manual median uncertainties vs. $2 \mathrm{~km}$ for automated). However, if we compare hypocentral locations for common events between the two catalogs when the uncertainty in the automated catalog is less than $0.5 \mathrm{~km}$, we find that on average spatial differences between the corresponding events in the two catalogs are only $2 \mathrm{~km}$ and maximum spatial differences are less than $15 \mathrm{~km}$. In other words, by limiting the automated catalog to only those events that meet a strict low uncertainty requirement, we achieve similar results between the catalog of manually identified seismic events and catalog of automated seismicity, with far less time needed to construct the automated catalog. Based on this result, we then utilize the automated location procedure on all 18 months of data (Figure 2) and restrict the final catalog to events with all three spatial uncertainties less than 0.5 .

To provide further context for our 18-month catalog of automated earthquake locations, we make detailed comparisons to the spatial distribution of events from several older studies. The first catalog we utilize is for aftershocks in the 18 months following the 2003 January 22 (Mw 7.2) Tecomán earthquake. This catalog was originally compiled based on $\mathrm{P}$ and S waveforms from a 12-station, short-period seismic network (RESCO) operated by the University of Colima (Schmitt et al., 2007). The second catalog we use was determined by using an array of autonomous hydrophone moorings in the eastern equatorial Pacific operated by the Pacific Marine Environmental Laboratory (PMEL) from 1996 to 2001 (Fox et al., 2001). Although our study region occurs outside this array, the close proximity leads to predicted standard errors on the order of $2 \mathrm{~km}$ for latitude and longitude. Comparison data sets indicate detection thresholds and accuracy better than the land networks for open ocean areas and results comparable to, or better than, the U.S. Navy Sound Surveillance System (Fox et al., 2001). We also compare with previous studies that analyze the aftershocks of the 1995 October 9 (Mw 8.0) Colima-Jalisco earthquake (Pacheco et al., 1997) and the 1973 January 30 (Mw 7.6) Colima earthquake (Reyes et al., 1979). In these cases, catalogs were not available so we compare the spatial distribution of our seismicity with seismicity digitized from figures in those previous studies of the 1995 and 1973 events. 


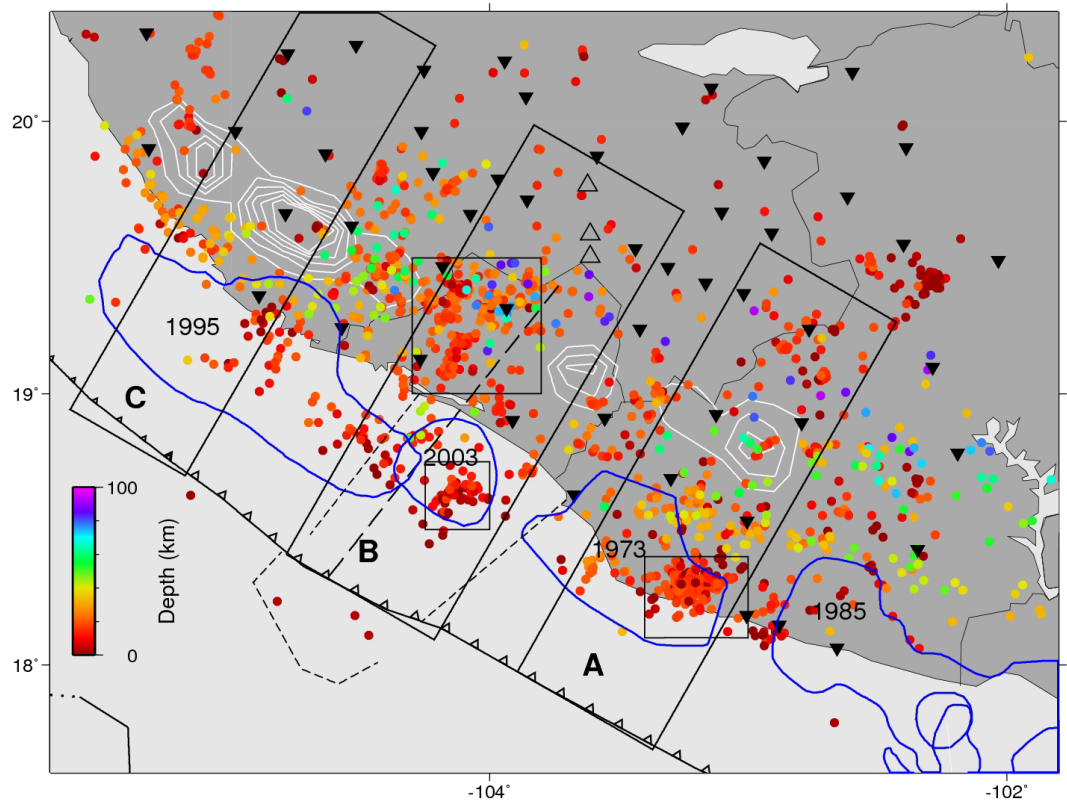

Figure 2. Map of seismicity (colored by depth) and non-volcanic tremor (white contours) located using the MARS PASSCAL deployment (inverted triangles). Major earthquake rupture zones are outlined in blue. Open triangles are volcanoes including Trans-Mexican Volcanic Belt (TMVB). Long dashed line near the edges of the 1995 and 2003 rupture zone indicates apparent subducted boundary between Rivera and Cocos plates (Andrews et al., 2011). 3 large boxes show areas of cross sections in Figure 5.3 smaller boxes indicate study focus areas with more dense seismicity for which temporal patterns are shown in Figures 6 and 9.

To gain additional perspective on the stresses at work in specific areas of interest we calculated fault plane solutions for events large enough to make reliable identifications of first motion polarities (nominally, $M>3.0$ ). To determine each focal mechanism we use FocMec, a Fortran program that, given specific input, searches the focal sphere and can report and plot solutions based on default or user-specified criteria (Snoke, 2003). Input files for FocMec were assembled using station information from Antelope database files and careful examination of first motion polarities in all available waveforms. Takeoff angles were estimated using the pseudo-bending method within tomoDD (Zhang and Thurber, 2003). We use the default criteria within FocMec to calculate a set of fault plane solutions for the lowest number of allowable polarity errors, and then take the median of these solutions as the focal mechanism for a specific event. This resulted in focal mechanisms for 6 events in the region inland of the 2003 rupture zone and for 5 events within the 1973 rupture zone. Considering the importance of these new focal mechanisms to our interpretations of each region, we also further refined the depth and location of these earthquakes through careful evaluation of each phase pick and forward modeling of the hypocentral depth.

\section{Results}




\subsection{Spatial Distribution of Seismicity and Estimated Depth of Subducting Slab Surface}

Our automated event location procedure produces nearly 1600 earthquake locations that meet our spatial uncertainty criteria over the 18-month period from the beginning of 2006 to the middle of 2007. As previously indicated, figure 2 shows the geographic distribution of seismicity based on our catalog of events. Epicenters are color coded to indicate depth, which helps illustrate that the majority of events occur in the upper $30 \mathrm{~km}$. Earthquakes below $70 \mathrm{~km}$ are more common in the eastern half of the study region and appear to outline the subducting Cocos plate, while events below $70 \mathrm{~km}$ are generally absent in the western half of the study region.

To help illustrate this change, we constructed slab contours (Figure 1, dotted lines) that focus on the spatial distribution of deeper seismicity in inland regions. We constructed a series of narrow (30 km wide) cross-sections following a 30-degree azimuth starting every $30 \mathrm{~km}$ along the trench. We sought to fit a line to the top of the seismicity representing the upper slab surface (Figure 3). At distances greater than $80 \mathrm{~km}$ from the trench, we restrict our attention to earthquakes below $25 \mathrm{~km}$ depth (circles) as those are most likely to be intraslab earthquakes within the subducting plate, whereas shallower events are more likely to be associated with the upper continental plate. The well-located seismicity in each cross-section was divided into $10 \mathrm{~km}$ depth ranges, and slab surface points were calculated using the furthest earthquake distance from the trench and the bottom of the depth range. To account for hypocentral uncertainty, choosing the bottom of the depth range is somewhat conservative and leaves a handful of earthquakes above the slab surface. Slab surface transects are constructed by connecting the points in each cross-section. This approximation is limited in a few cases where the slab dip appears to be changing rapidly over the $30 \mathrm{~km}$ cross-section width. Slab depth contours are constructed by connecting common depth points across all cross-sections and smoothing the resulting line.

The path of the $40 \mathrm{~km}$ depth contour moves abruptly further from the trench across the Colima Graben, highlighting a rapid shallowing of slab contours from east to west. The distinct change in the path of this contour correlates well with an extended trajectory of the line proposed to delineate the subducted Rivera-Cocos plate boundary (Andrews et al., 2011). The trend of the contours and correlation with the expected boundary suggest that the two plates have different trajectories soon after subduction, particularly near their proposed subducted boundary. In fact, there appears to be an area of more intense seismicity (cluster) in our catalog near the change in hypocentral patterns at depth, which may be a consequence of interaction between the two subducting plates and will be investigated further in section 3.3. 


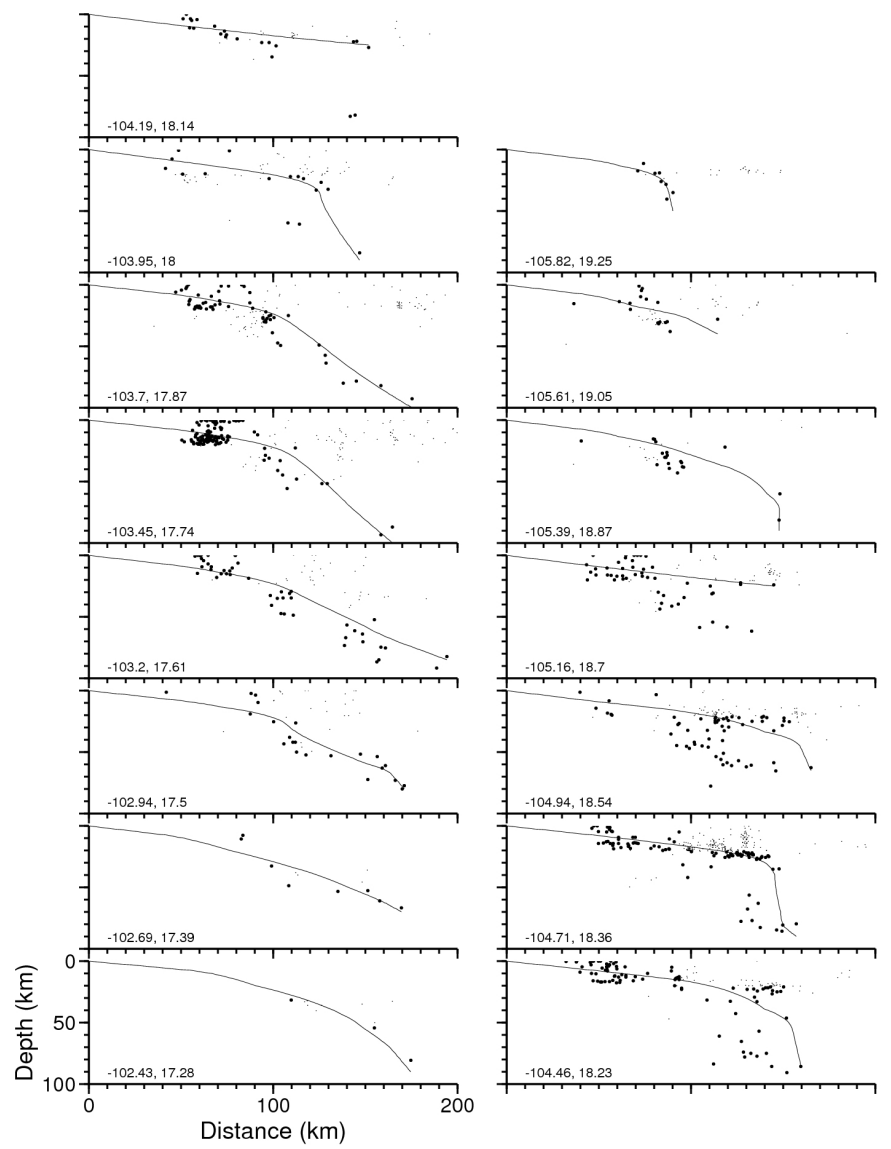

Figure 3. Cross-sections perpendicular to the trench (30ªzimuth) every $30 \mathrm{~km}$ along strike across our study region. Circles show subducting slab seismicity identified in this study, and the curve is the estimated top of the subducting slab.

Although the density of seismicity is variable across the array, we also find two areas with an increased intensity of shallower seismicity offshore that appear to be associated with the rupture zones of the large 1973 and 2003 megathrust earthquakes (Figure 2). Additional seismicity in a megathrust rupture zone continuing 3 years after the 2003 January 22 earthquake is perhaps not surprising, but pronounced seismicity occurring over 30 years after the 1973 earthquake was not anticipated. A more detailed examination of this seismicity cluster and whether it varies over time will be presented in the next section.

\subsection{Seismicity Patterns Near the 1973 January 30 (Mw 7.6) Colima Earthquake}

Though the MARS deployment began over three decades after the 30 January 1973 (Mw 7.6) Colima earthquake, we identify an area of more dense seismicity (a cluster) at the eastern end of the estimated 1973 rupture zone (Figure 4d) (Reyes et al., 1979). When compared with epicenters from that initial study of aftershocks from 4 to 22 days after the 1973 rupture, we find that our cluster matches a denser group of the aftershocks recorded (Figures 4a,d). This observation raises the question whether this cluster is an indication of long-lasting aftershock activity, an indication of pre-event foreshock activity, or an indication that seismicity is relatively continuous in this region. 
To investigate these hypotheses we seek to find whether this cluster represents a region of gradually decaying seismicity, a recent increase in seismicity, or persistent seismicity. We can make some inferences about the seismic activity over time by comparing our results with the PMEL catalog (Figure 4c) and the RESCO 2003 aftershock catalog (Figure 4b). In each case, we find there is an area of more intense seismicity towards the eastern end of the 1973 rupture zone although the PMEL events extend to the south from our cluster and the 2003 aftershocks from RESCO extend to the west. These extensions could be real variations in the source locations over time, but one might expect the PMEL locations to be biased in the north-south direction as the stations are all to the south, and the 2003 aftershock locations could be biased in the east-west direction as the stations are all to the west. When we examine the depth estimates of this cluster in the RESCO catalog relative to our catalog (Figures 6a,d), we find that the cluster follows the trajectory of the previously defined plate interface at $\sim 60 \mathrm{~km}$ distance from the trench in both cases (Pardo and Suarez, 1993).
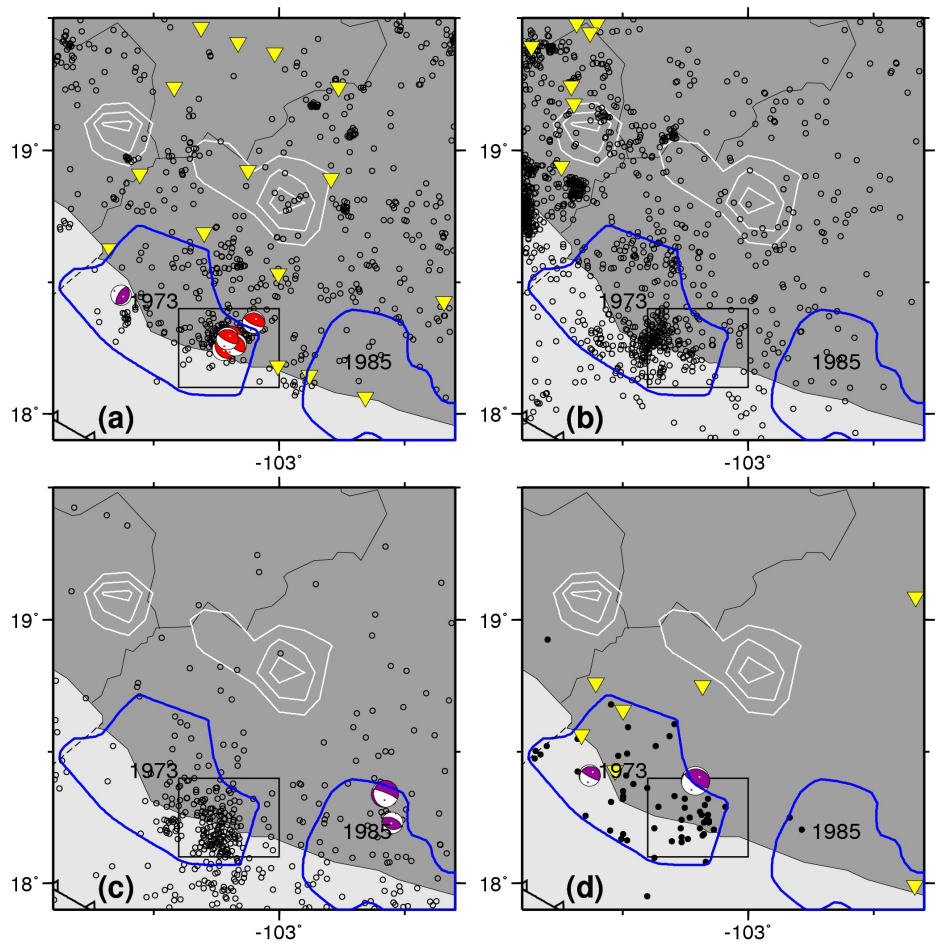

Figure 4. Maps showing epicenters in the 1973 rupture region over 4 different time periods. Yellow triangles show station locations used in each separate analysis, except for the PMEL hydrophones that are further to the south. Focal mechanisms are from Global CMT (purple) and our analysis (red). (a) Locations from our analysis of the 2006-2007 MARS data. (b) RESCO locations from the year and a half following the 2003 M8.0 earthquake to the west. (c) Locations using PMEL hydrophones from 1996-2001. (d) Aftershocks on days 4-22 following the 1973 event (Reyes et al., 1979). 

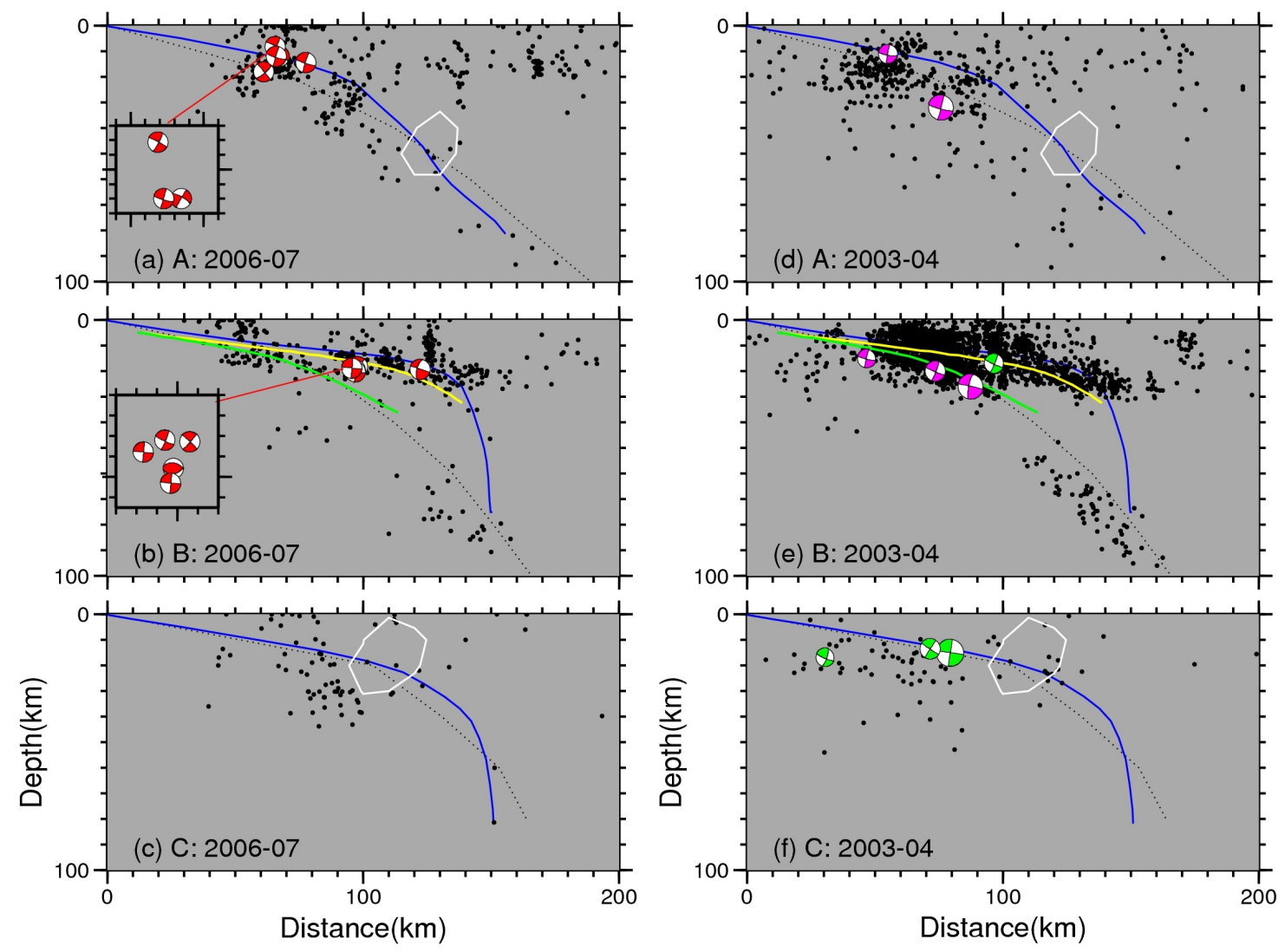

Figure 5. Cross-sections A-C showing earthquake hypocenters (dots), approximate region of non-volcanic tremor (white ovals) and side view of focal mechanisms (beach balls). Areas of each cross-section are shown in Figure 2 and roughly corresponding to the rupture zones of the 1973 (a,d) 2003 (b,e) and 1995 (c,f) megathrust earthquakes. Hypocenters from our analysis of the 2006-2007 MARS data (a-c). Hypocenters from the RESCO catalog in the 18 months following the 2003 event (d-f). White curves outline where there are at least 5 tremor hypocenters within a $10 \times 10 \mathrm{~km}$ area. Solid blue lines represent our proposed plate interface, while the dotted lines are the plate interface proposed by Pardo and Suarez (1995). Yellow and green lines are the interfaces of the Rivera and Cocos plates, respectively, based on double difference relocation of Andrews et al. (2011). There is no vertical exaggeration. Focal mechanisms from the Rivera (green) and Cocos (pink) plates following the 2003, 1995, and 1973 earthquakes indicate thrust mechanisms along the plate interface. Focal mechanisms from our analysis of events from the MARS catalog are in red and primarily indicate thrust mechanisms near the plate interface as well.

While we cannot confirm that the cluster of seismicity is persistent in precisely the same location over 30 years following the rupture, the possibility calls into question whether the events from the initial study are truly aftershocks that mark the 1973 rupture zone or whether that temporary deployment happened to catch a zone of persistent seismicity which may have been accelerated by a nearby rupture. 
Further investigation reveals the patterns of activity in this cluster are consistent between the three catalogs covering different time periods (Figure 6). In regards to the temporal distribution of events, the overall pattern is a constant, gradual undulation between more and less activity with no clear mainshock-aftershock sequences, suggesting that activity here is more like a swarm (Holtkamp and Brudzinski, 2011). Although each catalog is likely to produce somewhat different magnitudes considering the different station configurations and processing routines, we find relatively consistent magnitudes recorded in each case, with maximum magnitudes near 4 (verified by the ISC catalog), and regular occurrence of magnitude 3 events. Considering the atypical temporal patterns of this cluster, we further analyzed the hypocentral locations and focal mechanisms of the five largest events within this cluster during the MARS deployment in order to see if seismicity is associated with movement on the plate interface. This analysis reveals thrust mechanisms (Figure 7) consistent with the direction of subduction. There is one normal mechanism too, but it follows the same fault plane consistent with a recent finding that subduction thrust slip can dynamically "overshoot" and then be followed by normal slip to relieve the stress (Ide et al., 2011). Both the automated seismicity from our catalog and the fault planes of our focal mechanisms follow the plate interface, with the mechanisms situated between $\sim 10-20 \mathrm{~km}$ depth (Figure 5a). The prevalence of thrust events at depths near the apparent plate interface provides further evidence that the denser seismic activity is caused by subduction processes. Our ability to interpret these results is limited since we do not know what the patterns of seismicity were like prior to the 1973 earthquake, nor do we have detailed locations of events occurring between 1974 and 1995 . However, the similarity of cluster location over 30 years, the fairly continuous activity of the cluster as seen during temporary deployments, focal mechanisms indicating thrust faulting located at the plate interface, and that the majority of other events with depth estimates occur on or very near the plate surface suggest that this is a long-standing feature of the megathrust. Thus it appears that stress on this portion of the plate interface is relieved relatively frequently over time and that this swarm-like behavior at the eastern end of the 1973 rupture zone could represent a lateral barrier to megathrust rupture (Holtkamp and Brudzinski, 2014). 

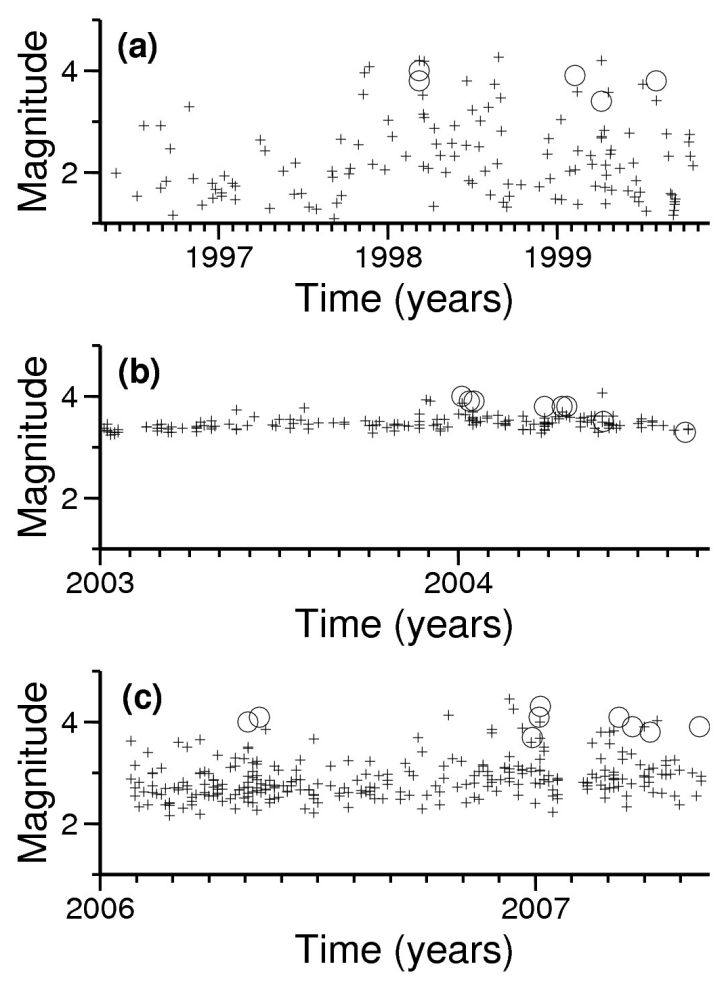

Figure 6. Temporal patterns of seismicity in a section of the 1973 rupture zone (Figure 4, box). Since magnitudes of local catalogs are less constrained, circles indicate magnitudes of events in the ISC global catalog. (a) Times and magnitudes from the PMEL catalog for 1996-2001. (b) Times and magnitudes from the RESCO catalog for 2003-2004.5. (c) Times and magnitudes from our analysis of the MARS data for 2006-2007.5.

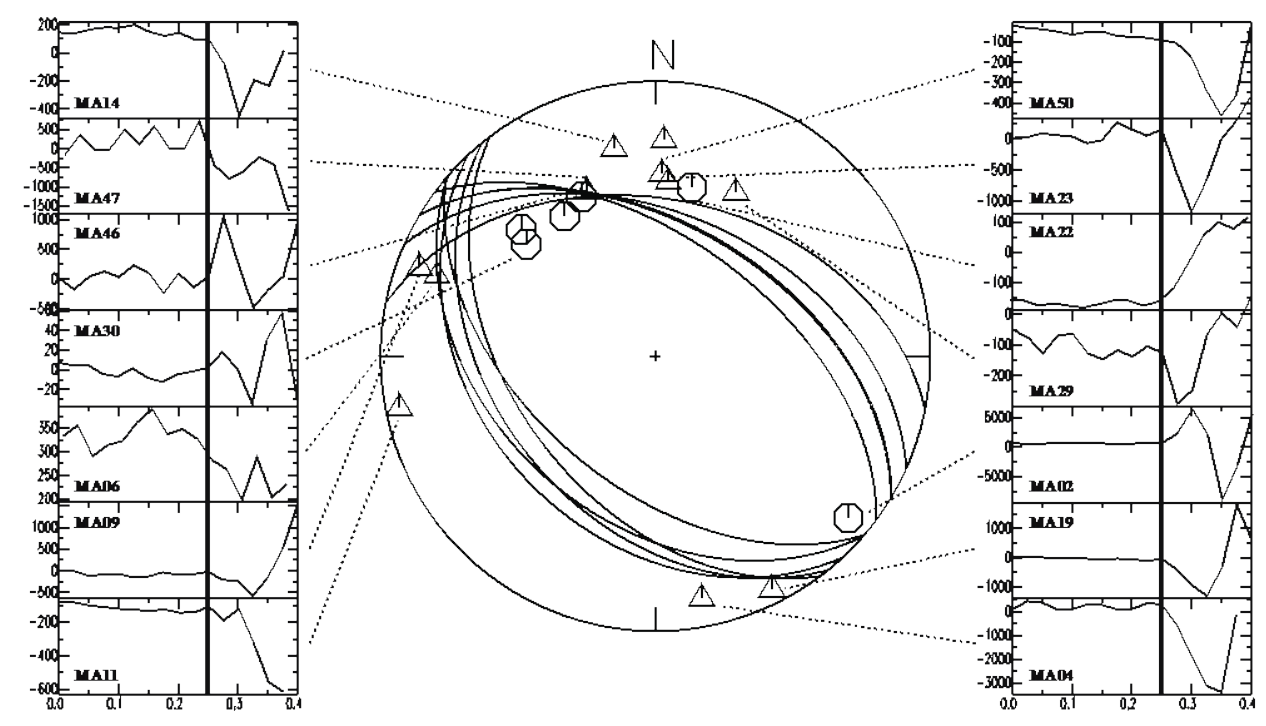

Figure 7. Fault plane solutions and selected first arrivals for one of the thrust events in the 1973 cluster (Figure 5a) overlaid on station polarity data. Compressional stations are represented by circles; dilatational stations are represented by triangles 


\subsection{Seismicity Patterns Near the 2003 January 22 (Mw 7.2) Tecomán Earthquake}

The MARS deployment began only 3 years after the 2003 January 22 (Mw 7.2)

Tecomán earthquake, so we sought to evaluate the seismicity trends in our catalog relative to that rupture and early aftershocks. As noted in the previous section, there is a cluster of seismicity in our catalog that occurs at the southern edge of the megathrust rupture zone (Figure 8a, small box), where the rupture zone is estimated from finite element inversions of measured coseismic GPS displacements (Schmitt et al., 2007). To further investigate the potential relationship between the cluster we observe and the 2003 earthquake, we make comparisons between our catalog of the MARS deployment and the RESCO catalog that encompasses the 18 months following the 2003 earthquake (Figure $8 \mathrm{~b})$. This catalog reveals a dense region of aftershocks immediately north of the cluster identified in our later catalog. Intriguingly, the area of most prominent aftershock activity in the RESCO catalog lies between the shoreline and the corresponding location of our cluster and shows very little seismicity in our catalog despite a similar station configuration. Instead, our cluster seems to extend the 2003 aftershock region slightly to the south. Global CMT solutions for a pair of events in our cluster reveal thrust mechanisms, supporting the notion that they represent slip on the plate interface at the up-dip edge of the 2003 rupture zone. Although we do not have a source location model for the afterslip associated with the 2003 earthquake, preliminary indications suggest that some afterslip occurred offshore and updip (Schmitt et al., 2007). Although we cannot rule it out, it seems unlikely that the effect of afterslip would be driving the migration of seismicity in this direction three years after the mainshock. 

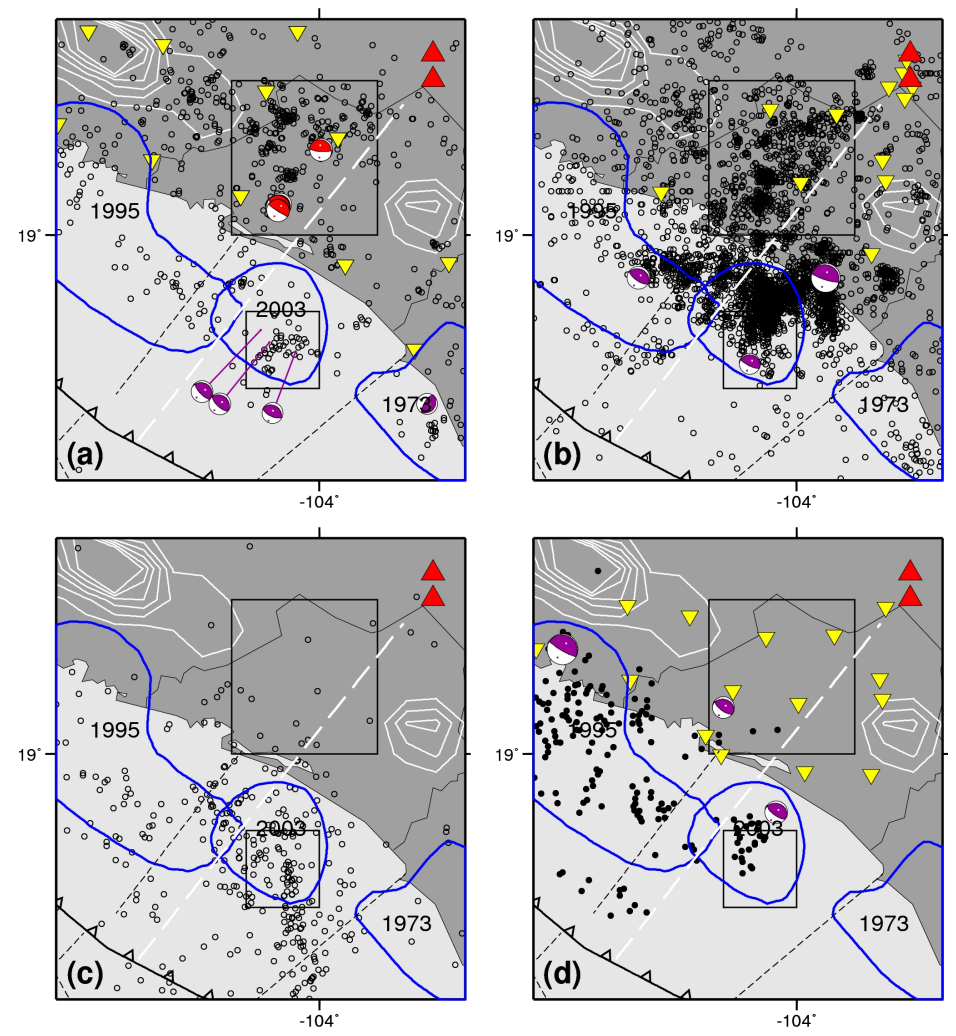

Figure 8. Maps showing epicenters (black circles) in and around the 2003 rupture zone over 4 different time periods. Megathrust rupture zones are blue lines as in Figure 2. White contours are tectonic tremor locations. Focal mechanisms are from Global CMT (purple) and our analysis (red) and indicate thrust mechanisms. Long dashed white line near the edges of the 1995 and 2003 rupture zone indicates apparent subducted boundary between Rivera and Cocos plates (Andrews et al., 2011). Red triangles are volcanoes, and yellow triangles show station locations used in each analysis, except for the PMEL hydrophones that are further to the south. (a) Earthquakes locations from our analysis of the 2006-2007 MARS data. (b) RESCO locations from the year and a half following the 2003 event. (c) Locations using PMEL hydrophones from 1996-2001. (d) Aftershocks following the 1995 earthquake (Pacheco et al., 1997).

We note that our cluster still occurs $\sim 50 \mathrm{~km}$ from the trench and there is very little seismicity in the region updip of our cluster in any of the catalogs (Figure 8), such that we wonder whether the upward progression of seismicity along the megathrust will continue. The geodetic analysis of the 2003 rupture found no slip updip of $9 \mathrm{~km}$ (Schmitt et al., 2007), consistent with the lack of seismicity seen in the other catalogs. While some have considered the near trench region to be aseismic, recent great earthquakes like the 2011 Tohoku, Japan event suggest these shallowest sections of the megathrust are locked for many earthquake cycles and release in catastrophic, tsunamigenic events (Ide et al., 2011). An alternative possibility for the updip extent of our cluster is that it marks a portion of the interface with more persistent seismicity, like recurring earthquake swarms 
(Holtkamp and Brudzinski, 2011). If this were the case, an area of more intense seismicity would persist after the traditional tapering off in magnitude and frequency of earthquakes that is typical of aftershock seismicity, which should dissipate in the first few years following the mainshock. To test this idea, we also examine the locations determined by the PMEL hydrophone array from 1996-2001 (Figure 8c), and the spatial patterns of the 1995 aftershock sequence (Figure 8d). These datasets find seismicity located in the eventual 2003 rupture zone close to our cluster, but we are unable to discern whether the subtle differences in spatial distribution of events between these catalogs are above the location uncertainties or whether they occur on the same patch of the fault. Finally, we examine the time history of events in our cluster region for evidence of persistent seismicity. Figure 9 shows event magnitudes over time in the 3 available catalogs for the region enclosed in the small box (Figures 9a,b,c). While there is some evidence for ongoing small $(\mathrm{M} 2$ ) background seismicity, the majority of larger earthquakes $(M>3)$ occur as part of mainshock-aftershock sequences, including the two largest events in 2006 (Figure 9) that have thrust mechanisms (Figure 8a). In any case, further monitoring of this portion of the plate interface is warranted to help discern between locally persistent seismicity or anomalous updip seismicity in a seismically locked zone, which have vastly different hazards implications.
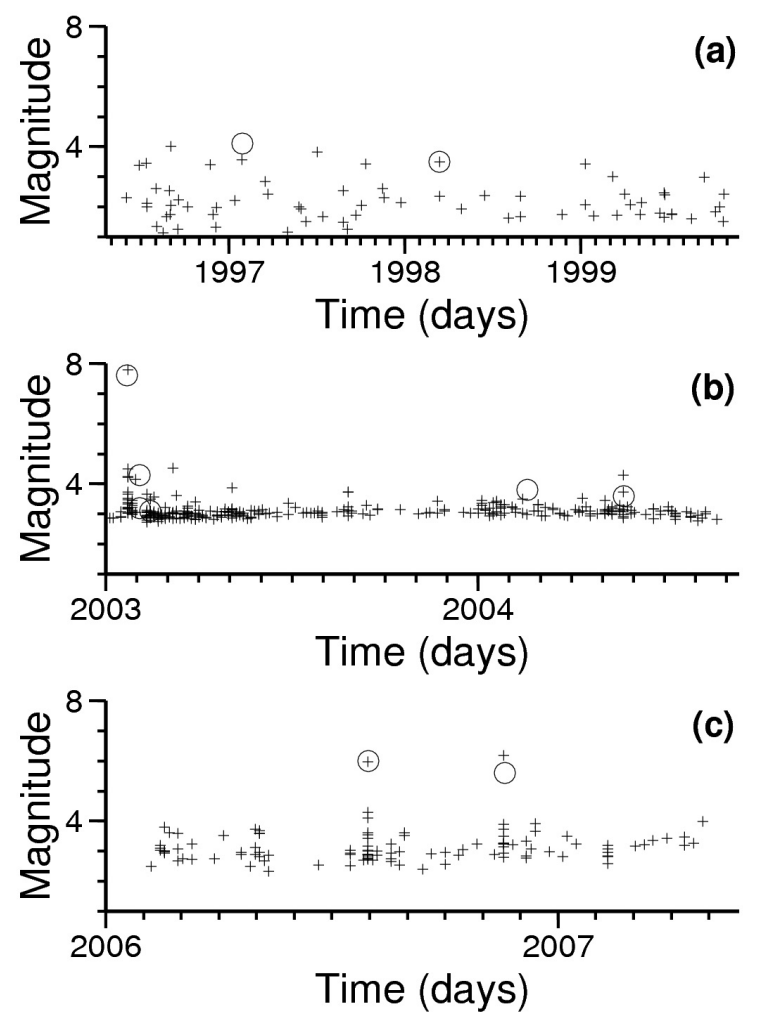

Figure 9. Temporal patterns of seismicity in a portion of the 2003 rupture zone (Figure 8, small box). Since magnitudes of local catalogs are less constrained, circles indicate magnitudes of events in the ISC global catalog or from moment tensor inversions. (a) Times and magnitudes from the PMEL catalog for 1996-2001. (b) Times and magnitudes from the RESCO catalog for 2003-2004.5. (c) Times and magnitudes from our analysis of the MARS data for 2006-2007.5. 
Our catalog also reveals several more intense patches of seismicity onshore north of the 2003 rupture zone (Figure 8a, large box). The locations of these clusters appear to outline a rectangular area of pronounced aftershock productivity following the 2003 earthquake. Preliminary estimates of afterslip following the 2003 earthquake suggest that is primarily propagated downdip along the plate interface over time, which could help explain why this inland region is active during the 18 months immediately following the event, as shown in the RESCO catalog (Figure 8b), though it is unlikely that it would have a strong influence on the seismicity observed during the MARS deployment. However, there are two competing hypotheses for the nature of the fault causing this zone of seismicity: it is related to a shallow dipping Rivera plate interface (Andrews et al., 2011) or it is a result of the Tamazula fault zone that marks the western edge of the Colima Graben (Garduño-Monroy et al., 1998). We find several pieces of evidence point to these events marking the trace of the Rivera plate. Based on double difference relocation of 2003 aftershocks (Andrews et al., 2011), the onshore seismicity has a distinct eastern limit interpreted as the boundary between the shallow dipping Rivera and the more steeply dipping Cocos plates (dashed line, Figure 8). Although we only plot the original 2003 aftershock locations in Figure 8b, this abrupt eastern termination is still prominent near $-104^{\circ}$ longitude.

Cross-sections through both our catalog and the 2003 aftershocks show that this inland zone of events follows a distinctive shallow dipping trajectory consistent with the trajectory of a shallow Rivera plate interface (Figures 5b,e). We note there is also an isolated zone of steeper dipping deeper earthquakes in this cross-section that suggests a possible overlap between the shallow dipping Rivera plate and steeper dipping Cocos plate. However, Andrews et al. (2011) found that higher-resolution relative relocation through a double difference algorithm applied to the RESCO dataset was required to discriminate the eastern steeper dipping seismicity of the Cocos from the western shallower dipping Rivera plate. So we interpret the apparent overlap between the seismic zones in Figure 5b as an artifact of the traditional location routine employed in this study similar to the initial RESCO study (Figure 5e), and that future double difference relocation of the MARS dataset would be needed to further resolve this issue. Since Andrews et al. (2011) only studied events above $30 \mathrm{~km}$ depth, one possibility that could be examined with such a future study is whether the Cocos plate is side-by-side with the Rivera plate at shallow depth but curves under the Rivera plate at depth.

The double difference relocation of 2003 aftershocks identified a boundary between the subducting plates by differentiating the sharp change in slab dip from the northwest (shallow) to the southeast (steep) (Andrews et al., 2011) (dashed line, Figures 2 and 8). Slab contours created using the MARS catalog are consistent with the location of this sharp change in slab dip (Figure 1). The contours clearly indicate that while the Rivera and Cocos plate reach $20 \mathrm{~km}$ depth at relatively the same distance from the trench, the Cocos plate then descends at relatively consistent intervals while the Rivera plate does not dip to $40 \mathrm{~km}$ depth until significantly further inland. The path of the $40 \mathrm{~km}$ contour line moves abruptly toward the trench at approximately the location where Andrews et al. indicate the subducted Rivera-Cocos boundary is located (Figure 1), supporting our conclusion that the Rivera plate is significantly shallower along the whole 
inland area where we are observing more intense seismicity.

Regional thrust mechanisms also support the hypothesis that this shallow trend in seismicity is related to the Rivera plate. We determined six focal mechanisms for events from the MARS catalog in the inland region. Previously determined mechanisms for the 1995 mainshock and a large aftershock as well as our newly determined mechanisms are all located at $\sim 15-20 \mathrm{~km}$ depth within the observed seismicity (Figure $5 \mathrm{~b}$ ). These are primarily thrust mechanisms with fault planes following the shallow dipping trajectory of seismicity from our automated catalog and consistent with motion on a subduction interface (Figure 5b, inset). The exception is one normal fault oriented perpendicular to the other thrust mechanisms, which indicates that there is could be some less prominent normal faulting in the crust associated with the Colima Graben. However, our analysis reveals an important new thrust mechanism farthest east within the shallow dipping band of seismicity (Figure 10). This is one of the best constrained focal mechanisms we have presented due to the large number of arrivals that surround the nodal planes. While thrust faults can happen in the crust, the Tamazula Fault Zone is a north-south trending normal faulting feature that cannot explain an east-west striking thrust mechanism at this depth. We believe these observations represent the most important new evidence that this zone of seismicity requires a shallow dipping Rivera plate interface across this region. We also believe the gap in tectonic tremor provides additional support for this, as tremor could be inhibited at the discontinuity between subducting plates (Ide et al., 2010; Fagereng and Diener, 2011).

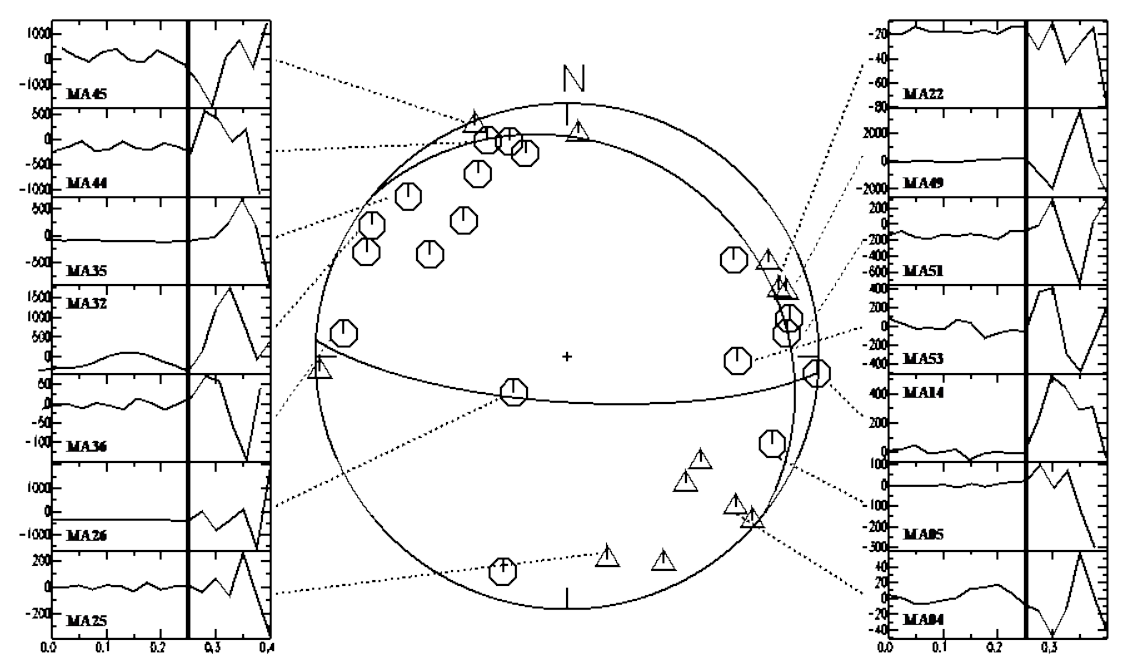

Figure 10. Fault plane solution and selected first arrivals for the easternmost mechanism in the inland zone (Figure 5b) overlaid on station polarity data. Compressional stations are represented by circles; dilatational stations are represented by triangles.

When we look more closely at the seismicity occurring in the northwestern area of the study region, our results further support the idea that there is a relatively narrow region along-strike where the shallow dipping trajectory exists. In cross-section $\mathrm{C}$ to the 
northwest (Figure 2), a cluster of events at distance $90 \mathrm{~km}$ from the trench (Figure 5c) is more prominent than seismicity available following the 2003 earthquake (Figure 5f). This cluster is $\sim 15 \mathrm{~km}$ deeper than seismicity at this distance from the trench in cross-section $\mathrm{B}$, indicating that the region of shallow dipping Rivera plate does not extend to this location. Figure 3 shows that the northwestern transition to steeper dip occurs over a relatively narrow along-strike distance.. The contours of the Rivera slab clearly steepen as we move further to the northwest, supporting a steeper dipping Rivera plate as well (Figure 1). Cross-section A at the southeast end of the study region (Figure 2) shows a more contiguous band of seismicity extending to deeper depths consistent with our slab contours (Figure 1) and with a steeper slab dip (Figures 5a,d) associated with the subducting Cocos plate. It appears that there is a small portion of this Cocos plate trajectory captured at the bottom of cross-section B (Figures 5b,e).

Previous seismological studies of deeper portions of the subduction zone have suggested that Rivera plate is more steeply dipping than the Cocos plate (Yang et al 2009; Pardo and Suarez 1993). Those results were supported by evidence consistent with the Rivera plate being detached beneath the TMVB with the remaining slab consequently rolling back and steepening the shallow plate interface (Ferrari, 2004; Soto et al., 2009). Thus, it is somewhat surprising to see that the Rivera plate initially has a more shallow dip than the Cocos plate in our study using MARS data and in the study by Andrews et al. (2011) using RESCO data. Andrews et al. (2011) suggests that the Rivera plate has a smaller radius of curvature than the Cocos plate, which would have been difficult to recognize in previous studies that had little resolution of the shallower plate trajectory. This creates a more gently dipping seismogenic zone than the Cocos plate at shallow depths before the plate bends rapidly to have a steeper dip, consistent with slab detachment and rollback of the Rivera slab, at greater depths.

\subsection{Spatial Anti-correlation of Seismicity and Tectonic Tremor}

In this section, we want to draw attention to an intriguing relationship in the broader spatial patterns of the seismicity catalog we have constructed. We find that earthquake locations appear to be generally anti-correlated with regional tectonic (nonvolcanic) tremor. The locations of tremor are based on a complimentary study using a semi-automated process to identify prominent energy bursts in envelope waveforms of the full MARS dataset, and analyst-refined relative arrival times are inverted for source locations using a 1-D velocity model (Schlanser et al., 2010). This approach is similar to that utilized in the Oaxaca region of Mexico (Brudzinski et al., 2010), and the results in our study region are similar to that of Ide (2012) (Figure 11). There are slight differences between the two studies as the one we focus on uses analyst refinement of strongest tremor bursts whereas Ide's technique is automated to look for correlations at all times.

In both studies, tremor occurs in a northwest-southeast trending corridor that is $\sim 20 \mathrm{~km}$ wide and roughly parallel to a zone of seismicity that straddles the coastline. Tremor depths are poorly constrained (Brudzinski et al., 2010; Schlanser et al., 2010), but we assume they occur along the plate interface based on higher resolution imaging in several subduction zones (Brown et al., 2005). Our slab surface estimates indicate that tremor occurs between 15-30 km depth northwest of the Colima Graben and 40-60 km 
depth to the southwest. As suggested by Schlanser et al. (2010), we believe this is due to the warmer and cooler temperatures of the younger Rivera and older Cocos plates, respectively. This depth offset based on temperature of the subducting plate is similar to that seen for slow slip in the Hikurangi subduction zone of New Zealand (McCaffrey et al., 2008).

The anti-correlation between tremor and seismicity in our study region is demonstrated as two prominent zones of tremor activity located near $-103^{\circ}$ and $-105^{\circ}$ longitude, and seismicity is sparse in both zones (Figure 2), and the gap between the tremor zones is punctuated by more prolific seismicity near $-104^{\circ}$ longitude. The anticorrelation can also be observed in cross-sectional view, where the tremor zone is outlined where there are at least 5 tremor hypocenters within a $10 \times 10 \mathrm{~km}$ cross-sectional area (Figure 5). Tremor is prominent in zones of reduced seismicity in cross-sections A and $\mathrm{C}$, but is generally absent in cross-section $\mathrm{B}$ where seismicity is prominent.

To help quantify the apparent anti-correlation between tremor and earthquakes, we calculated the number of earthquakes and tremor locations within $0.15 \times 0.15$ degree spatial bins within the tremor corridor from $-105.1^{\circ}$ to $-102.9^{\circ}$ longitude. Figure 11 shows how the amount of tremor within a given spatial bin is small when the amount of earthquakes is high, and vice versa. The decreasing monotonic trend between the amount of tremor and number of earthquakes is not linear so we use a Spearman's rank correlation. The resulting correlation coefficient is $-56 \%$ with a $14 \%$ standard error, indicating that the anti-correlation between earthquakes and tremor along this corridor is statistically significant.

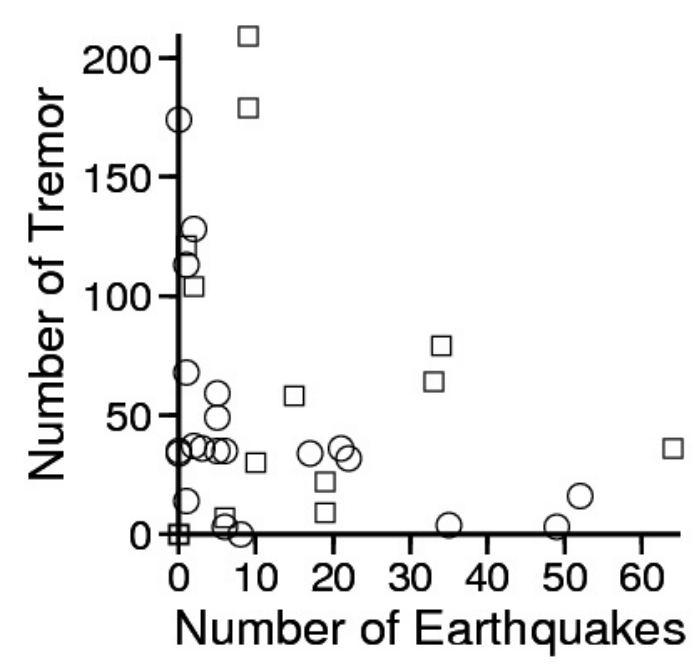

Figure 11. Comparison of tectonic tremor and earthquake locations determined along the 20-km wide band of tremor in our study region. Tremor locations are from Schlanser et al. (2010, circles) and Ide (2012, squares). The anti-correlation is statistically significant (-56\% $\pm 14 \%)$ using a Spearman’s rank correlation.

The anti-correlation pattern between earthquakes and tremor is notable, but similar patterns have been seen in the Oaxaca region of Mexico about $500 \mathrm{~km}$ to the east (Brudzinski et al., 2010) and in the Cascadia subduction zone (Gomberg and Grp, 2010). In previously described cases, it has been suggested that earthquakes and tremor 
represent different modes of frictional behavior, such that the physical conditions on the fault modulate whether the fault moves as earthquakes or tremor. One possible modulator is the amount of pore fluid pressure as recent studies have found extremely low seismic velocity anomalies and high Poisson's ratio anomalies associated with the source zone of tectonic tremor (Audet et al., 2009; Song et al., 2009). An additional complication to consider are unusual variations in slab morphology, as very shallow slab dip or tears in the slab have been suggested in this region (Yang et al., 2009; Andrews et al., 2011).These scenarios could change the physical conditions or P-T path for the plate interface, disturbing the megathrust fault or causing dehydration at different depths that may limit the conditions needed to generate tremor (Ide et al., 2010; Fagereng and Diener, 2011).

\section{Discussion}

Our study demonstrates that the Rivera plate shallows before curving steeply, and that microplate separation can happen rapidly after subduction such that this scenario should be considered in other regions with abrupt changes in slab contours, tremor gaps, or segmentation in surface geology. In our region, rapid tearing is consistent with the trenchward location of the Colima Volcano and with geochemical traces of suboceanic mantle in near coastal hot springs (Taran et al., 2013). Additionally, the most prominent tremor gap in this region occurs where we argue for a shallow subducting Rivera plate, providing us with cause to believe that the shallow depth of the plate may be resulting in conditions that are not favorable for tremor production. The broader region of shallow Rivera plate also brings the megathrust further inland, suggesting that larger magnitude earthquakes could occur in this region and could occur closer to population centers. Finally, the flatter subduction angle could also be contributing to the formation of the higher elevations of the Jalisco Block in the sense that a broader region of subduction interface contact would result in more shortening of the overriding plate, similar to those subduction processes contributing uplift in the overriding plate observed in the western United States and South America (Spencer, 1996; Jordan and Allmendinger, 1986).

\section{Conclusions}

The MARS deployment was primarily designed to investigate the seismic structure of the subducting Cocos and Rivera plates at the Middle America Trench along western Mexico, but our study demonstrates that it also provides an opportunity to examine the seismicity patterns over an 18-month inter-seismic time span in 2006-2007. One of the more intriguing patterns in the seismicity is an anti-correlation with tectonic tremor, which suggests there is a boundary along the megathrust fault that marks the transition from one type of slip to the other.

We find several prominent areas of more intense seismicity that appear to be related to patterns associated with previous large megathrust earthquakes in this region. The cluster found in the region of the 1973 (Mw 7.6) megathrust earthquake corresponds with a set of the 1973 aftershock locations. Comparing with two additional earthquake catalogs in this region indicates that a cluster of activity has been relatively persistent in a similar location for over a decade recently and it may have been a consistent feature since at least 1973. Examination of the cluster earthquakes through each of the data sets shows gradual undulations in activity, similar magnitudes, and no clear mainshock-aftershock 
sequences, characteristic of swarm-like activity. The apparent long-standing nature of this feature suggests that release of accumulated elastic strain in this portion of the plate interface is relatively frequent. All but one of the mechanisms determined for this cluster are thrust mechanisms located near the plate interface with fault planes following the expected dip of the plate, providing further support for seismicity related to persistent subduction processes. This raises questions as to whether this set of aftershocks is appropriate for characterizing the rupture area of the mainshock. Given its swarm-like temporal characteristics and association with the plate interface, we suggest that this cluster could represent a lateral barrier to megathrust rupture in this region (Holtkamp and Brudzinski, 2014).

Ongoing aftershocks of the 2003 M 7.2 rupture appear to make up the bulk of a cluster seen in 2006-2007 around the mainshock rupture, but some epicenters from 20062007 are grouped towards the southern edge of the zone, suggesting that seismicity patterns could be migrating updip over time. The onshore clusters from 2006-2007 also correspond heavily with seismicity from a 2003 aftershock study, including one group each of shallow and deep seismicity. These separate groups likely represent the different Rivera and Cocos plate interfaces, as supported by previous double difference relocations (Andrews et al., 2011) and the sharp change in the path of the $40 \mathrm{~km}$ slab contour created using the MARS catalog. The six thrust mechanisms we determine from events in the MARS catalog are located within the observed band of shallow seismicity, including one significantly farther east than those previously available, which suggests that the more intense seismicity is a result of thrust motion on a shallow dipping Rivera plate interface. Both the trend of the automated seismicity and the shallow dip of the thrust mechanisms follow a shallow dipping trajectory consistent with the plate interface. The gap in tectonic tremor that also occurs in this location is consistent with this boundary as tremor could be inhibited by the discontinuity between the subducting plates. Combining our results with previous studies suggests the Rivera plate separates from the Cocos plate soon after subduction and ultimately bends more rapidly through a smaller radius of curvature that is consistent with Rivera slab rollback.

\section{Acknowledgements}

Support for this work was provided by NSF grants EAR-0847688 (MB) and the IRIS Internship Program (EA). This study was entirely possible thanks to the MARS project team that collected such a high quality dataset. S. Grand was particularly helpful in providing access to the data. S. Schmitt provided access to the RESCO locations. S. Bilek provided additional guidance on the calculation of fault plane solutions and $\mathrm{H}$. DeShon assisted in the calculation of take-off angels. F. Núñez-Cornú, M. Ishii, C. DeMets, S. Dougherty, E. Currano, B. Currie, F. Vega, and 2 anonymous reviewers provided comments that helped improve the manuscript.

\section{References}

Andrews, V., Stock, J., Ramírez Vázquez, C.A., Reyes-Dávila, G., 2011. Doubledifference Relocation of the Aftershocks of the Tecomán, Colima, Mexico Earthquake of 22 January 2003. Pure and Applied Geophysics, 168, 1331-1338. 
Audet, P., Bostock, M.G., Christensen, N.I., Peacock, S.M., 2009. Seismic evidence for overpressured subducted oceanic crust and megathrust fault sealing. Nature, 457, 76-78.

Bandy, W., Kostoglodov, V., Hurtado-Díaz, A., and Mena, M., 1999. Structure of the southern Jalisco subduction zone, Mexico, as inferred from gravity and seismicity. Geofísica Internacional, 38(3), 127-136.

Bandy, W., Mortera-Gutierrez, C., Urrutia-Fucugauchi, J., Hilde, T. W. C., 1995. The subducted Rivera-Cocos Plate Boundary: Where is it, what is it, and what is its relationship to the Colima Rift?. Geophysical Research Letters, 22(22), 3075-3078.

Brown, J. R., Beroza, G. C., Ide, S., Ohta, K., Shelly, D. R., Schwartz, S. Y., Rabbel, W., Thorwart, M., Kao, H., 2009. Deep low-frequency earthquakes in tremor localize to the plate interface in multiple subduction zones. Geophysical Research Letters, 36(19).Brudzinski, M. R., Cabral-Cano, E., Correa-Mora, F., DeMets, C., MárquezAzúa, B., 2007. Slow slip transients along the Oaxaca subduction segment from 1993 to 2007. Geophysical Journal International, 171(2), 523-538.

Brudzinski, M.R., Hinojosa-Prieto, H.R., Schlanser, K.M., Cabral-Cano, E., ArciniegaCeballos, A., Diaz-Molina, O., DeMets, C., 2010. Nonvolcanic tremor along the Oaxaca segment of the Middle America subduction zone. Journal of Geophysical Research-Solid Earth, 115(B8).

Courboulex, F., Singh, S. K., Pacheco, J. F., Ammon, C. J., 1997. The 1995 ColimaJalisco, Mexico, Earthquake (Mw 8): A study of the rupture process. Geophysical Research Letters, 24(9), 1019-1022.

DeMets C. and Traylen, S., 2000. Motion of the Rivera plate since 10 Ma relative to the Pacific and North American plates and the mantle: Tectonophysics, 318, 119-159.

DeMets, C., Wilson, D. S., 1997. Relative motions of the Pacific, Rivera, North American, and Cocos plates since $0.78 \mathrm{M}$. Journal of Geophysical Research, 102(B2), 2789-2806.

Dougherty, S. L., Clayton, R. W., Helmberger, D. V., 2012. Seismic structure in central Mexico: Implications for fragmentation of the subducted Cocos plate. Journal of Geophysical Research, 117, B09316, doi:10.1029/2012JB009528.

Dougherty, S. L. and Clayton, R. W., 2014. Seismicity and structure in central Mexico: Evidence for a possible slab tear in the South Cocos plate. Journal of Geophysical Research: Solid Earth. 119, 3447.

Dziewonski, A. M., Ekström, G., Salganik, M. P., 1997. Centroid-moment tensor solutions for October-December 1995. Physics of the Earth and Planetary Interiors, 101(1-2), 1-12.

Ekström, G., Dziewonski, A. M., Maternovskaya, N. N., Nettles, M., 2005. Global seismicity of 2003: centroid-moment-tensor solutions for 1087 earthquakes. Physics of the Earth and Planetary Interiors, 148, 327-351.

Escobedo, D., Pacheco, J. F., and Suárez, G., 1998. Teleseismic body-wave analysis of the 9 October, $1995(\mathrm{Mw}=8.0)$, Colima-Jalisco, Mexico earthquake, and its largest foreshock and aftershock: Geophysical Research Letters, 25(4), 547-550.

Fagereng, Å., Diener, J.F.A., 2011. Non-volcanic tremor and discontinuous slab dehydration. Geophysical Research Letters 38(15), 1-5.

Ferrari, L., 2004. Slab detachment control on mafic volcanic pulse and mantle heterogeneity in central Mexico. Geology, 32(1), 77-80. 
Fox, C.G., Matsumoto, H., Lau, T.-K.A., 2001. Monitoring Pacific Ocean seismicity from an autonomous hydrophone array. Journal of Geophysical ResearchSolid Earth, 106(B3), 4183-4206.

Garduño-Monroy, V. H., Saucedo-Girón, R., Jiménez, S., Gavilanes-Ruiz, J. C., CortésCortés, A., Uribe-Cifuentes, R. M., 1998. La Falla Tamazula, limeite suroriental del bloque Jalisco, y sus relaciones con el complejo volcánico de Colima, Mexico.

Revista Mexicana de Cienceias Geológicas, 15(2), 132-144.

Gomberg, J., Grp, C. 2007 W., 2010. Slow-slip phenomena in Cascadia from 2007 and beyond: A review. Geological Society of America Bulletin, 122, 963-978.

Gutscher, M. A., Spakman, W., Bijwaard, H., Engdahl, E. R., 2000. Geodynamics of flat subduction: Seismicity and tomographic constraints from the Andean margin. Tectonics. 19, 833.

Holtkamp, S.G., Brudzinski, M.R., 2011. Earthquake swarms in circum-Pacific subduction zones. Earth and Planetary Science Letters, 305, 215-225.

Holtkamp, S.G., Brudzinski M.R., 2014. Megathrust earthquake swarms indicate frictional changes which delimit large earthquake ruptures. Earth and Planetary Science Letters, 390, 234-243.

Hutton, W., DeMets, C., Sánchez, O., Suárez, G., Stock, J., 2001. Slip kinematics and dynamics during and after the 9 October $1995 \mathrm{Mw}=8.0$ Colima-Jalisco earthquake, Mexico, from GPS geodetic constraints. Geophysical Journal International, 146(3), 637-658.

Husker, A. and Davis, P. M., 2009. Tomography and thermal state of the Cocos plate subduction beneath Mexico City. Journal of Geophysical Research. 114, B04306.

Ide, S., 2012. Variety and spatial heterogeneity of tectonic tremor worldwide. Journal of Geophysical Research, 117(B3), B03302, doi:10.1029/2011JB008840.

Ide, S., Baltay, A., Beroza, G.C., 2011. Shallow dynamic overshoot and energetic deep rupture in the $2011 \mathrm{Mw} 9.0$ Tohoku-Oki earthquake. Science, 332(6036), 14261429.

Ide, S., Shiomi, K., Mochizuki, K., Tonegawa, T., Kimura, G., 2010. Split Philippine Sea plate beneath Japan. Geophysical Research Letters, 37(21), 1-6.

Jordan, T. E., and Allmendinger, R. W., 1986. The Sierras Pampeanas of Argentina: A modern analogue of Rocky Mountain Foreland Deformation. American Journal of Science, 286, 737-764.

Kim, Y., Clayton, R. W., Jackson, J. M., 2010. Geometry and seismic properties of the subducting Cocos plate in central Mexico. Journal of Geophysical Research: Solid Earth. 115, B06310.

Kogstoglodov, V. and Bandy, W., 1995. Seismotectonic constraints on the convergence rate between the Rivera and North American plates. Journal of Geophysical Research. 100, 17977-17989.

Kostoglodov, V., Husker, A., Shapiro, N. M., Payero, J. S., Campillo, M., Cotte, N., Clayton, R., 2010. The 2006 slow slip event and nonvolcanic tremor in the Mexican subduction zone. Geophysical Research Letters. 37, L24301.

Larson, K. M., Kostoglodov, V., Miyazaki, S., Santiago Santiago, J. A., 2007. The 2006 aseismic slow slip event in Guerrero, Mexico: New results from GPS. Geophysical Research Letters, 34(13), L11309. 
McCaffrey, R., Wallace, L. M., \& Beavan, J., 2008. Slow slip and frictional transition at low temperature at the Hikurangi subduction zone. Nature Geoscience, 1(5), 316320.

Melbourne, T., Carmichael, I., DeMets, C., Hudnut, K., Sanchez, O., Stock, J., Suarez, G., Webb, F., 1997. The geodetic signature of the M8.0 Oct. 9, 1995, Jalisco subduction zone. Geophysical Research Letters, 24(6), 715-718.

Mendoza, C., 1993. Coseismic slip of two large Mexican earthquakes from teleseismic body waveforms: Implications for asperity interaction in the Michoacan Plate Boundary Segment. Journal of Geophysical Research-Solid Earth, 98(B5), 81978210.

Mendoza C. and Hartzell, S., 1999. Fault-slip distribution of the 1995 Colima-Jalisco, Mexico, earthquake. Bulletin of the Seismological Society of America, 89(5), 13381344.

Pacheco, J., Singh, S.K., Dominguez, J., Hurtado, A., Quintanar, L., Jimenez, Z., Yamamoto, J., Gutierrez, C., Santoyo, M., Bandy, W., Guzman, M., Kostoglodov, V., Reyes, G., Ramirez, C., 1997. The October 9, 1995 Colima-Jalisco, Mexico earthquake (Mw 8): An aftershock study and a comparison of this earthquake with those of 1932. Geophysical Research Letters, 24(17), 2223-2226.

Pardo, M. and Suárez, G., 1993. Steep Subduction Geometry of the Rivera Plate beneath the Jalisco Block in Western Mexico. Geophysical Research Letters 20(21), 23912396

Pardo, M., Suarez, G., 1995. Shape of the subducted Rivera and Cocos plates in southern Mexico: Seismic and tectonic implications. Journal of Geophysical Research-Solid Earth, 100(B7), 12357-12373.

Pavlis, G. L., Vernon, F., Harvey, D., \& Quinlan, D., 2004. The generalized earthquakelocation (GENLOC) package: an earthquake-location library. Computers \& Geosciences, 30(9-10), 1079-1091.

Payero, J. S., Kostoglodov, V., Shapiro, N., Mikumo, T., Iglesias, A., Pérez-Campos, X., Clayton, R. W., 2008. Nonvolcanic tremor observed in the Mexican subduction zone. Geophysical Research Letters, 35(7), L07305.

Peláez Gaviria, J. R., Mortera Gutiérrez, C. A., Bandy, W. L., Michaud, F., 2013. Morphology and magnetic survey of the Rivera-Cocos plate boundary of Colima, Mexico. Geofísica Internacional, 52(1), 73-85.

Pérez-Campos, X., Kim, Y. H., Husker, A., Davis, P. M., Clayton, R. W., Iglesias, A., Pacheco, J. F., Singh, S. K., Manea, V. C., Gurnis, M., 2008. Horizontal subduction and truncation of the Cocos Plate beneath central Mexico. Geophysical Research Letters. 35, L18303.

Reyes, A., Brune, J.N., Lomnitz, C., 1979. Source Mechanism and Aftershock Study of the Colima, Mexico Earthquake of January 30, 1973. Bulletin of the Seismological Society of America 69(6), 1819-1840.

Rosas-Elguera, J., Ferrari, L., Garduño-Monroy, V. H., Urrutia-Fucugauchi, J., 1996. Continental boundaries of the Jalisco block and their influence in the PlioceneQuaternary kinematics of western Mexico. Geological Society of America, 24(10), 921-924. 
Schlanser, K M, Brudzinski, M R, Kelly, N J, Grand, S P, Cabral-Cano, E, DeMets, C, 2010. Episodic tremor and slip along the Rivera and Cocos subduction zones of southern Mexico. Eos Trans. AGU, 90, S23A-2088.

Schmitt, S.V., DeMets, C., Stock, J., Sanchez, O., Marquez-Azua, B., Reyes, G., 2007. A geodetic study of the 2003 January 22 Tecoman, Colima, Mexico earthquake. Geophysical Journal International, 169, 389-406.

Scholz, C. H., 2002. The Mechanics of Earthquakes and Faulting. Cambridge University Press: Cambridge. 471 pp.

Singh, S. K., Ponce, L., and Nishenko, S. P., 1985. The Great Jalisco, Mexico, Earthquakes of 1932: Subduction of the Rivera Plate. Bulletin of the Seismological Society of Amercia, 75(5), 1301-1313.

Song, T.R.A., Helmberger, D.V., Brudzinski, M.R., Clayton, R.W., Davis, P., PerezCampos, X., Singh, S.K., 2009. Subducting Slab Ultra-Slow Velocity Layer Coincident with Silent Earthquakes in Southern Mexico. Science, 324, 502-506.

Soto, G.L., Ni, J.F., Grand, S.P., Sandvol, E., Valenzuela, R.W., Speziale, M.G., González, J.M.G., Reyes, T.D., 2009. Mantle flow in the Rivera-Cocos subduction zone. Geophysical Journal International, 179, 1004-1012.

Snoke, J. A., 2003. FOCMEC: FOCal MEChanism Determinations. Package URL: http://www.geol.vt.edu/outreach/vtso/focmec/.

Spencer, J. E., 1996. Uplift of the Colorado Plateau due to lithosphere attenuation during Laramide low-angle subduction. Journal of Geophysical Research, 101(B6), 1359513609.

Suarez, G., Escobedo, D., Bandy, W., Pacheco, J. F., 1999. The 11 December, 1995 earthquake ( $\mathrm{Mw}=6.4)$ : Implications for the present-day relative motion on the Rivera-Cocos plate boundary. Geophysical Research Letters, 26(13), 1957-1960.

Taran, Y., Morán-Zenteno, D., Inguaggiato, S., Varley, N., Luna-González, L. 2013. Geochemistry of thermal springs and geodynamics of the convergent Mexican Pacific margin. Chemical Geology, 339, 251-262.

Yagi, Y., Mikumo, T., Pacheco, J., and Reyes, G., 2004. Source Rupture Process of the Tecomán, Colima, Mexico Earthquake of 22 January 2003, Determined by Joint Inversion of Teleseismic Body-Wave and Near-Source Data. Bulletin of the Seismological Society of America, 94(5), 1795-1807.

Yang, T., Grand, S.P., Wilson, D., Guzman-Speziale, M., Gomez-Gonzalez, J.M., Dominguez-Reyes, T., Ni, J., 2009. Seismic structure beneath the Rivera subduction zone from finite-frequency seismic tomography. Journal of Geophysical Research, 114, B01302.

Zhang, H., Thurber, C. H., 2003. Double-Difference Tomography: The Method and Its Application to the Hayward Fault, California. Bulletin of the Seismological Society of America, 93(5), 1875-1889. 